\title{
Temperature affects interaction of visual and vibrational cues in parasitoid host location
}

\section{Journal Article}

Author(s):

Kroder, Stefan; Samietz, Jörg; Dorn, Silvia

Publication date:

2007

Permanent link:

https://doi.org/10.3929/ethz-b-000003027

Rights / license:

In Copyright - Non-Commercial Use Permitted

Originally published in:

Journal of Comparative Physiology A 193(2), https://doi.org/10.1007/s00359-006-0181-y 


\title{
Temperature affects interaction of visual and vibrational cues in parasitoid host location
}

\author{
Stefan Kroder • Jörg Samietz • Silvia Dorn
}

Received: 30 March 2006 / Revised: 28 September 2006 / Accepted: 7 October 2006 / Published online: 3 November 2006

(C) Springer-Verlag 2006

\begin{abstract}
Parasitoid host location in nature is facilitated by simultaneously using different information sources. How multisensory orientation on the same spatial scale is influenced by environmental conditions is however poorly understood. Here we test whether changes in reliability of cues can cause parasitoids to alter multisensory orientation and to switch to cues that are more reliable under extreme temperatures. In the ichneumonid wasp Pimpla turionellae, multisensory use of thermally insensitive vision and thermally sensitive mechanosensory host location by vibrational sounding (echolocation on solid substrate) was investigated with choice experiments on plant-stem models under optimum temperature $\left(18^{\circ} \mathrm{C}\right)$, at high- $\left(28^{\circ} \mathrm{C}\right)$ and low-temperature limits $\left(8^{\circ} \mathrm{C}\right)$ of vibrational sounding. Temperature affected relative importance of vibrational sounding whereas visual orientation did not vary. At $18^{\circ} \mathrm{C}$, parasitoids used visual and vibrational cues with comparable relative importance. At 8 and $28^{\circ} \mathrm{C}$, the role of vibrational sounding in multisensory orientation was significantly reduced in line with decreased reliability. Wasps nearly exclusively chose visual cues at $8^{\circ} \mathrm{C}$. The parasitoids switch between cues and sensory systems depending on temperature. As overall precision of ovipositor insertions was not
\end{abstract}

S. Kroder $\cdot$ J. Samietz $\cdot$ S. Dorn

Institute of Plant Sciences, Applied Entomology,

ETH Zurich, 8092 Zurich, Switzerland

J. Samietz $(\square)$

Swiss Federal Research Station Agroscope

Changins-Wädenswil, Schloss, P.O. Box 185,

8820 Wädenswil, Switzerland

e-mail: joerg.samietz@acw.admin.ch affected by temperature, the parasitoids fully compensate the loss of one cue provided another reliable cue is available on the same spatial scale.

Keywords Host location - Multisensory orientation · Parasitoid $\cdot$ Temperature $\cdot$ Vibration

\section{Introduction}

Host location is a key process for tropic interactions between parasitoids and their hosts in which both sides evolve strategies in response to each other. While hosts evolve strategies to avoid detection (Vet et al. 1991; Vinson 1998), the parasitoids may refine their sensory systems or increase the number of information sources to locate and recognize hosts. The latter may involve plant-derived and host-derived signals that parasitoids perceive using sensory systems for olfactory, contact chemical, visual, or mechanosensory cues (for review see Godfray 1994). The relative importance of cues can vary with their accessibility and reliability during the host searching process (Wellings 1993; Völkl 2000; Schwörer and Völkl 2001): During the in-flight orientation of the searching parasitoid (i.e. host habitat location), the employed cues need to be accessible over a long range. At shorter distances and after landing on a host microhabitat, other cues become increasingly important with their accessibility. Whereas the accessibility is therefore mainly affected by the spatial scale, the reliability can largely depend on environmental factors. Being the degree of information provided with respect to the potential host (e.g. presence, identity, density, availability and suitability) the reliability is determined by the abiotic and biotic environment-as 
for example volatile emission depends on wind, vibrations on attenuation by the substrate, and vision depends on light intensity. In this respect, the simultaneous use of cues improves reliability and success of host location as the number of information sources is increased and uncertainty is reduced (Wäckers and Lewis 1994; Battaglia et al. 2000; Fischer et al. 2001; Stireman 2002). Although in nature different information sources are available at the same time and allow for multisensory orientation, the vast majority of studies on parasitoid host location is focused on a single cue only (e.g. Michaud and Mackauer 1994; Wäckers et al. 1998; Dutton et al. 2000; Rott et al. 2005). Some studies have so far investigated the interaction between visual and chemical cues in the same stage of host searching (e.g. Battaglia et al. 1993, 2000; Wäckers and Lewis 1994; Morehead and Feener 2000; Stireman 2002). More likely many, or even all host location processes are based on multisensory orientation including several cues, which the parasitoids are able to combine according to habitat and environmental conditions. However, whether and how parasitoids are able to switch between cues and sensory systems on the same spatial scale depending on environmental factors influencing reliability is hitherto unknown.

During host location, the parasitoid Pimpla turionellae (L.) (Hymenoptera: Ichneumonidae) is able to trace endophytic lepidopteran pupae by visual orientation (Fischer et al. 2003b, 2004a, b) as well as by vibrational sounding (Wäckers et al. 1998; Fischer et al. 2003a). The latter is a mechansosensory mechanism in which female wasps transmit self-produced vibrations on plant material (echolocation on solid substrate) and locate immobile hidden hosts by signal modifications sensed with the subgenual organs (Otten et al. 2002). This mechanism is especially established in pupal parasitoids of endophytic hosts where other cues are quantitatively reduced or not reliable enough (Broad and Quicke 2000). Visual orientation for potential endophytic hosts can, for example, be based on tunnelling damage, lesions or entrance holes (Pfannenstiel et al. 1992; Smith et al. 1993; Potting et al. 1997).

Pimpla turionellae is widely distributed in temperate regions in which the species appears from early spring to late autumn. The temperature typically varies from 5 to $25^{\circ} \mathrm{C}$ throughout the season and sometimes even throughout the day. The parasitoid seems to prefer temperatures around $18-20^{\circ} \mathrm{C}$ for mechanosensory host location (Samietz et al. 2006). Studied under moderate ambient temperatures, $P$. turionellae females use both visual and mechanosensory cues simultaneously for short-range host location and the two senses interact, resulting in an additive accuracy (Fischer et al.
2001). When the two cues are offered separately on artificial plant stem models, neither the visual nor the mechanosensory cue is favoured (Fischer et al. 2001). Both are used in this species and seem to be equally important for reliable host location on the investigated spatial scale. However, reliability of vibrational cues may change with changing environmental temperature since the performance and precision of vibrational sounding is obviously negatively influenced by suboptimal, especially too low ambient temperatures of $10^{\circ} \mathrm{C}$ or less (Kroder et al. 2006; Samietz et al. 2006). In insect vision, however, such negative temperature effects are unknown. The consequent changes in reliability of two relevant stimuli could cause parasitoids to alter their multisensory orientation and to switch to cues more reliable under extreme environmental conditions. To the authors' knowledge, this possibility was never investigated before.

The present study therefore tests this hypothesis with choice experiments under optimum temperature, as well as at the high- and low-temperature limits of vibrational sounding in the parasitoid $P$. turionellae. Furthermore it is tested, if the hypothesised switching to a single available cue under extreme conditions influences the overall precision of host location. In single female trials the influence of temperature on use of cues was tested with plant-stem models containing only visual and mechanosensory information. Models were analysed for quantity, location and precision of ovipositor insertions.

\section{Material and methods}

Parasitoid rearing

A laboratory strain of $P$. turionellae was reared on pupae of Galleria mellonella (Lepidoptera). Adults were confined in Plexiglas containers $\left(25 \times 25 \times 25 \mathrm{~cm}^{3}\right)$ and fed with honey and water. The wasps were kept at $15^{\circ} \mathrm{C}$, $70 \%$ relative humidity $(\mathrm{RH})$ with a photoperiod of 16D:8L. The host pupae were offered three times a week for ovipositing and host feeding. Parasitized pupae were stored at $24^{\circ} \mathrm{C}, 60 \% \mathrm{RH}$ and a photoperiod of $16 \mathrm{D}: 8 \mathrm{~L}$ until emergence of adults. The females were allowed to mate prior to the experiments and had host contact for the first time $24-48 \mathrm{~h}$ before the experiments started.

\section{Experimental procedures}

The searching behaviour of $P$. turionellae was exclusively investigated after landing on a host microhabitat at a short range. Plant stems with insect tunnels, leaf 
rolls and buds are potential lairs of host pupae, hence, any hollow rounded substrate elicits the typical searching behaviour after landing in $P$. turionellae with subsequent ovipositor insertions. In the experiments of the present study, a paper-cylinder (length: $125 \mathrm{~mm}$, diameter: $8 \mathrm{~mm}$ ) with both ends left open mimicked a hollow plant stem. The plant-stem model was made of airmail paper (ELCO Atlantic Clipper Air Mail, $45 \mathrm{~g} \mathrm{~m}^{-2}$, Allschwil, Switzerland) that completely covered a hidden host mimic and allowed the wasps a highly efficient use of vibrational sounding due to its low density (Fischer et al. 2003a). A cigarette filter $\left(15 \times 8 \mathrm{~mm}^{2}\right.$, Gizeh, Gummersbach, Germany) as solid section imitated the hidden host pupa and a black band as visual cue imitated damages by a potential host (Fig. 1). Under the homogeneous diffused light used in the experiments, the filter is not visible through the paper nor provides any shadowing that could be used for visual orientation of the wasps. The black band was printed on the airmail paper with a Lanier copier 7335 (Lanier, Horgen, Switzerland; output: 1,200 dpi). By using a toner copier with high temperature fixture and printing the black band at least 3 days before the trials, any emission of chemical stimuli was minimized so that in this experimental approach host location behaviour of the wasps is restricted to vibrational and visual cues. Thus, ovipositor insertions on such a plant-stem model can be attributed to vibrational sounding and visual orientation. Pimpline wasps show an analogous behavioural response with such models when compared to natural systems as for example stemborer pupae hidden in maize stems (Fischer et al. 2004a).

The trials were conducted at the moderate temperature of $18^{\circ} \mathrm{C}$ and at the extreme temperatures of 8 and $28^{\circ} \mathrm{C}$ where $P$. turionellae still employs vibrational sounding but with a significantly lower precision (Samietz et al. 2006). The experiments were conducted in a climate chamber under controlled conditions at test temperature, $60 \%$ rh and white fluorescent illumination. At least $1 \mathrm{~h}$ before the trials, the parasitoids (age 6-33 days) were acclimatized to the test conditions. During the trials, each female was individually exposed to a plant-stem model (Fig. 1) for $20 \mathrm{~min}$ in a plexiglass box $\left(18.5 \times 8.5 \times 7.5 \mathrm{~cm}^{3}\right)$. At the beginning of the

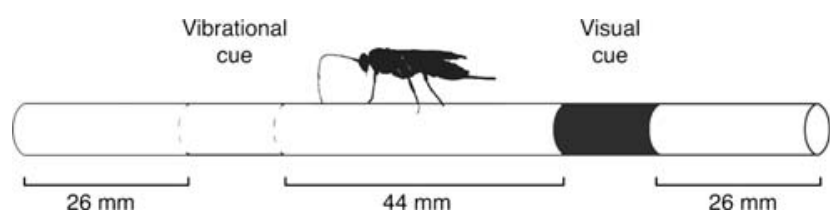

Fig. 1 Plant-stem model with vibrational (cigarette filter; width $=15 \mathrm{~mm}$ ) and visual cue (black band; width $=15 \mathrm{~mm}$ ) trial, each female was put at a random position within the box. The plant-stem models were horizontally fixed on white bottom of the box. Each individual and plantstem model was only used once so that the test females were associated to their plant-stem models for the subsequent analysis. This experimental set-up is comparable to a tritropic system with hidden host pupa and has been successfully used in a number of studies on visual and vibrational host location in this insect (e.g. Fischer et al. 2004a; Kroder et al. 2006; Samietz et al. 2006).

\section{Data analysis}

The ovipositor insertions of the parasitoids on the plant-stem models showed how the females use multisensory orientation during host location under changing temperatures. The plant-stem models were subdivided into 34 sections with section widths of $3.7 \mathrm{~mm}$. The cigarette filter as the vibrational cue and the black band as the visual cue contained four sections each. The cues were symmetrically located with a distance of seven sections to the outer ends of the plantstem model and 12 sections between the cues. This allowed scoring the position of the insertions relative to the two different cues on the plant-stem model. As detailed below, the insertions were quantitatively and qualitatively analysed for overall, vibrational and visual responsiveness, for relative importance of vibrational and visual cue during host location in each treatment, for precision and for insertion activity. All statistical analyses were conducted by using the statistical computation language $\mathrm{R}$ ( $\mathrm{R}$ Development Core Team 2005).

\section{Responsiveness}

The proportion of females responding with at least one ovipositor insertion to the plant-stem model was defined as overall responsiveness, and the proportions of females responding with insertions on the two cue areas were defined as vibrational and visual responsiveness, respectively. The nonparametric samples of overall, vibrational and visual responsiveness were compared by statistical tests for dichotomous data. According to the comparison of independent samples, a temperature effect on responsiveness was tested by the Fischer's probability test with adjusted $P$-values by the Hommel method ( $\mathrm{R}$ Development Core Team 2005). Visual and vibrational responsiveness were compared within each temperature treatment using the McNemar test for related samples. The vibrational responsiveness was divided by the visual responsiveness at each temperature, to visualize clearly the ratio 
between the two cues (Fig. 2). The overall responsiveness was displayed as percentage for each temperature treatment.

\section{Relative importance of cues}

The numbers of insertions on cue areas were divided by total number of insertions in each female revealing the relative importance of the cues during host location. During the trial time of $20 \mathrm{~min}$ females sometimes paused or discontinued searching activity and such discontinuations occurred more often with decreasing temperature. Therefore, to use females spending the majority of trial time in searching and to avoid disproportionately weighted insertions, only females with at least three insertions were valid for the comparisons of the relative importance. The desired sample size in each temperature treatment was therefore 20 females with at least three ovipositor insertions. The use of vibrational and visual cues was analysed for temperature dependence applying the nonparametric KruskalWallis $H$-test in accordance to the comparison between independent samples consisting of scaled data. Within each temperature, the preference for one of the cues was tested using the nonparametric Wilcoxon-test for related samples.

\section{Overall precision and insertion activity}

The insertion precision was quantified by analogy with the insertion bias method of Samietz et al. (2006) and Kroder et al. (2006) by measuring the average devia-

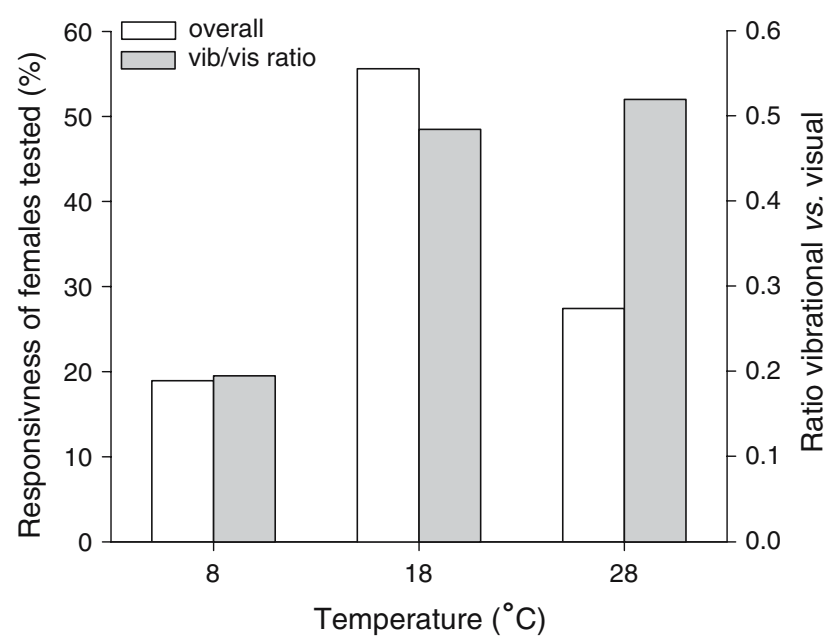

Fig. 2 Percentage of overall responsiveness (white; left $y$-axis) and ratio of vibrational versus visual responsiveness (grey; right $y$ axis) in Pimpla turionellae at 8,18 and $28^{\circ} \mathrm{C}$. Responsiveness is quantified as the females responding with at least one ovipositor insertion tion from the nearest cue centre. The insertion activity was expressed as the average number of insertions per responding female, and is therefore also an indicator for the general searching activity of the wasps. The significance of temperature effects on insertion precision and insertion activity were tested using the nonparametric Kruskal-Wallis $H$-test.

\section{Results}

\section{Responsiveness}

A total of 468 females were tested until the desired sample sizes were obtained. The highest overall responsiveness (with absolute number of responding females in brackets), i.e. the proportion of females inserting ovipositor at least once, with $55.7 \%$ (39 of 70 females) was found at the medium temperature of $18^{\circ} \mathrm{C}$ (Fig. 2), whereas responsiveness declined significantly to $19.0 \%$ (54 of 285 females) at $8^{\circ} \mathrm{C}$ and $27.4 \%$ (31 of 113 females) at $28^{\circ} \mathrm{C}$ (Fisher's test; $8-18^{\circ} \mathrm{C}: P<0.001 ; 18$ $28^{\circ} \mathrm{C}: P=0.031$ ). No significant difference was found between the overall responsiveness at the two extreme temperatures of 8 and $28^{\circ} \mathrm{C}$ (Fisher's test: $P=0.152$ ).

The responsiveness to the vibrational cue was generally lower than to the visual cue, and the vibrational responsiveness was at the most about the half of visual responsiveness. The ratio of vibrational versus visual cue varied from 0.20 at $8^{\circ} \mathrm{C}$ to 0.52 at $28^{\circ} \mathrm{C}$ (Fig. 2). Significant differences between vibrational and visual responsiveness were found in each temperature treatment (McNemar test; $8^{\circ} \mathrm{C}: \chi^{2}=20.9, P<0.001 ; 18^{\circ} \mathrm{C}$ : $\left.P=0.001 ; 28^{\circ} \mathrm{C}: P=0.017\right)$. Vibrational responsiveness was lowest at $8^{\circ} \mathrm{C}$ with only $2.81 \%$ responding females (Fisher's exact probability test; $8-18^{\circ} \mathrm{C}: P<0.001 ; 8$ $\left.28^{\circ} \mathrm{C}: P=0.005\right)$. It did not differ between 18 and $28^{\circ} \mathrm{C}$ despite the relatively different percentages of 22.9 and $11.5 \%$, respectively (Fisher's exact probability test: $P=0.104)$. In contrast, the visual responsiveness reflected a similar temperature dependence as the overall responsiveness, culminating with the significantly highest proportion of $47.1 \%$ at $18^{\circ} \mathrm{C}$ (Fisher's exact probability test; $\left.8-18^{\circ} \mathrm{C}: P<0.001 ; 18-28^{\circ} \mathrm{C}: P=0.030\right)$, and declining with decreasing and increasing temperature to $14.4 \%$ at $8^{\circ} \mathrm{C}$, and to $22.1 \%$ at $28^{\circ} \mathrm{C}$, without a significant difference between these extreme temperatures (Fisher's exact probability test: $P=0.145$ ).

\section{Relative importance of cues}

Although the wasps showed a relatively high variability in individual precision, the two cues on the plant-stem 
model showed a strong influence on host-location behaviour of the female wasps (Fig. 3). Overall 79.7\% of ovipositor insertions were observed directly on the two cue areas, surpassing the insertions on the remaining area significantly in all temperature treatments (Wilcoxon-test; $8^{\circ} \mathrm{C}: \quad Z=-4.70, \quad P<0.001 ; \quad 18^{\circ} \mathrm{C}$ : $\left.Z=-5.13, P<0.001 ; 28^{\circ} \mathrm{C}: Z=-4.00, P<0.001\right)$.

The quantitative ovipositor insertion activities on two cues offered on the plant-stem model were differently affected by temperature (Fig. 4). Focussing on the females with at least three insertions, a significant temperature effect was noted on the relative importance of the vibrational cue (Kruskal-Wallis $H$-test: $H_{2}=10,339$, $P=0.006$ ) but not on the visual cue (Kruskal-Wallis $H$ test: $\left.H_{2}=4,025, P=0.134\right)$. At the low temperature of $8^{\circ} \mathrm{C}$, the relative importance of vibrational sounding nearly disappeared. At the high temperature of $28^{\circ} \mathrm{C}$ it was also significantly lower than at $18^{\circ} \mathrm{C}$ (Fig. 4). In contrast, the highest relative importance of the visual cue was found at $8^{\circ} \mathrm{C}$, and the use of the two cues differed significantly at this temperature (Wilcoxon-test: $Z=-3.15, P=0.002)$. There was also a significant difference between the relative importance of vibrational and visual cue at the highest tested temperature at $28^{\circ} \mathrm{C}$ (Wilcoxon-test: $Z=-2.08, P=0.037$ ). At the medium temperature of $18^{\circ} \mathrm{C}$ both cues, vibrational and visual orientation, were equally used during host location by female wasps. No significant difference was found between the relative importance of visual and vibrational cue (Wilcoxon-test: $Z=-1.17, P=0.241$ ).

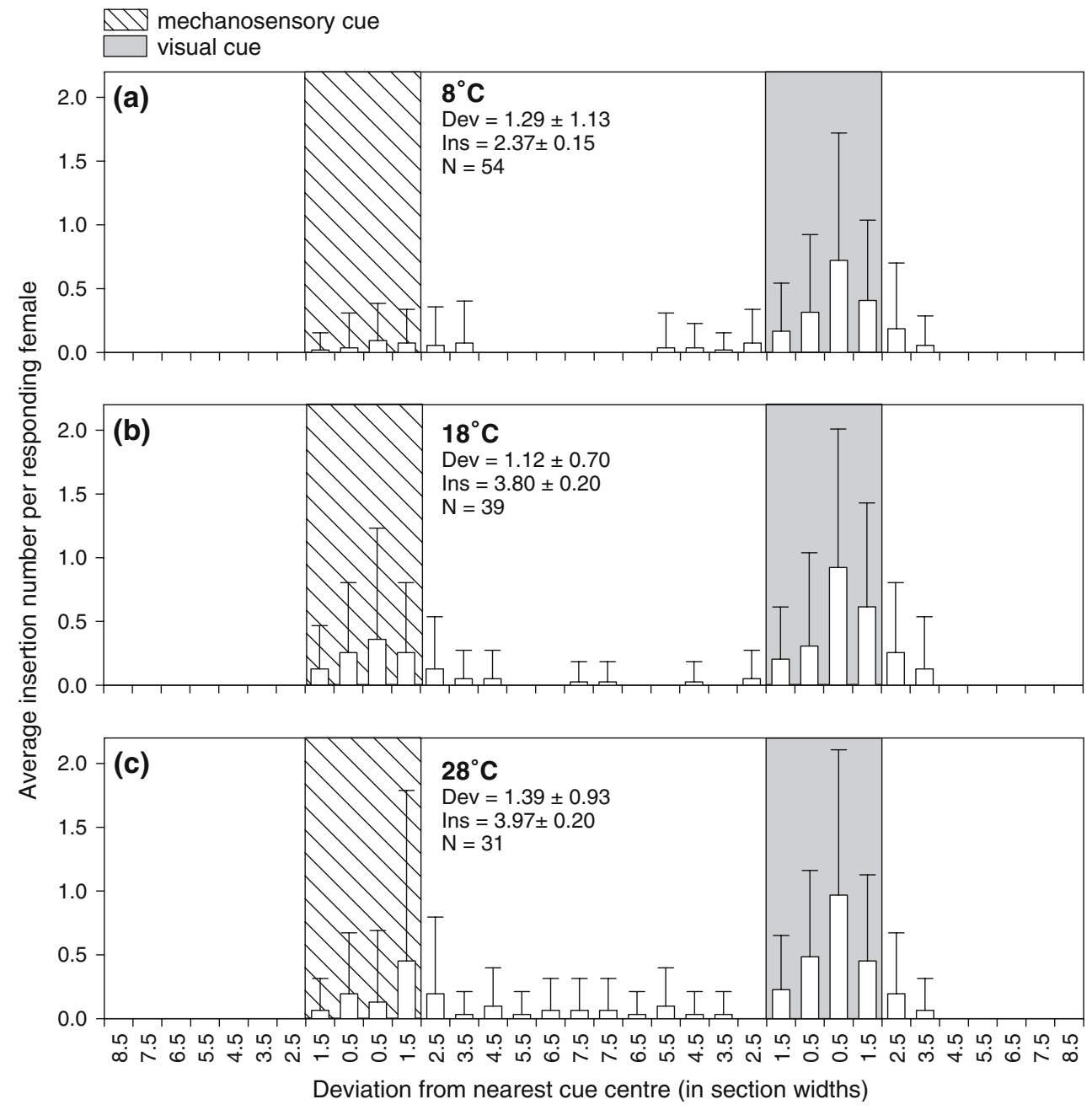

Fig. 3 Distribution of ovipositor insertions of Pimpla turionellae on plant-stem model with vibrational (cigarette filter) and visual cue (black band) at 8 (a), 18 (b) and $28^{\circ} \mathrm{C}$ (c). The bars and error bars show average number of insertions per responding female in each section (mean $\pm \mathrm{SD}$ ). The parameters are the mean devia- tion from the nearest cue centre in section widths (Dev; mean $\pm \mathrm{SD}$ ), average number of insertions into plant-stem model per responding female (Ins; mean $\pm \mathrm{SD}$ ) and the number of responding females $(n)$ 


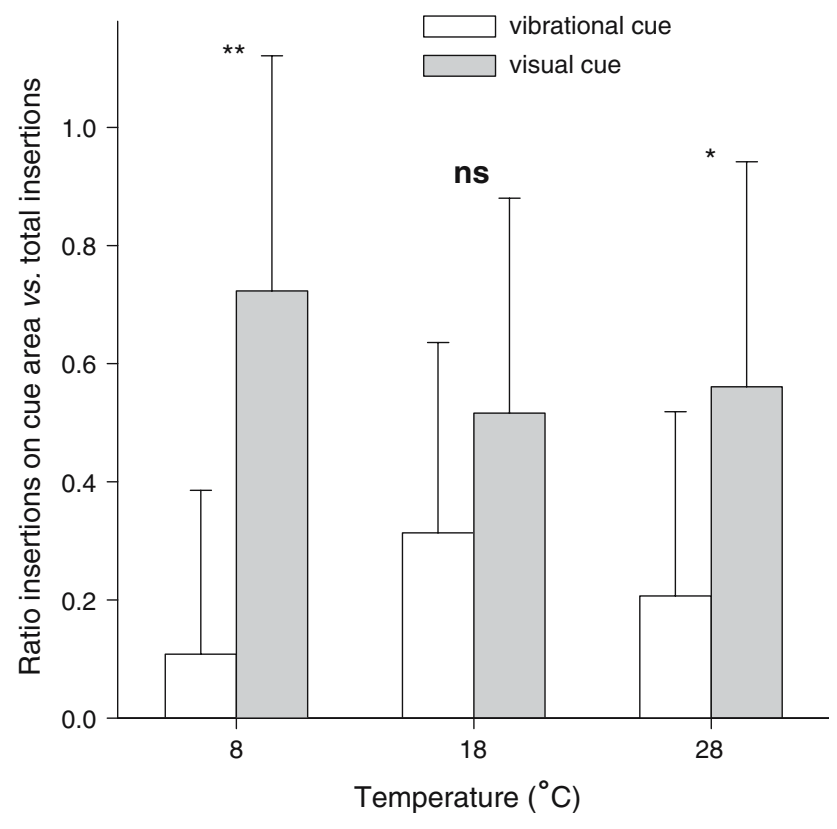

Fig. 4 Ratio between number of ovipositor insertions on cue areas and total number of insertions revealing the relative importance of vibrational (white; mean $\pm \mathrm{SD}$ ) and visual cue (grey) in Pimpla turionellae at 8,18 and $28^{\circ} \mathrm{C}$. Only females responding with at least three ovipositor insertions were included into this analysis. Asterisks indicate significant differences between vibrational and visual cue by Wilcoxon Signed Ranks test ( $n s$, not significant; ${ }^{*} P<0.05 ; * * P<0.01 ; n=20$ per treatment)

\section{Overall precision and insertion activity}

The overall precision of the parasitoids host location was not affected by ambient temperature (KruskalWallis $H$-test: $\left.H_{2}=1.21, P=0.55\right)$ but showed a high variability between individuals. They inserted their ovipositor with an average deviation (mean $\pm \mathrm{SD}$ ) from the cue centres of $1.26 \pm 0.96$ section widths in total (Fig. 3). The average deviations of individuals varied from 0.5 to 6.5 sections.

The insertion activity as the average number of insertions per responding female largely depended on ambient temperature (Kruskal-Wallis $H$-test: $\left.H_{2}=6.78, \quad P=0.034\right)$. Whereas parasitoids rarely inserted the ovipositor into the plant-stem model under the cold condition at $8^{\circ} \mathrm{C}$, they increased the activity with increasing temperature (Fig. 3 ).

\section{Discussion}

The present study provides clear evidence that parasitoids are able to combine different information sources in multisensory host location depending on the environmental conditions. They can switch between sensory systems when the reliability of one host location cue on the same spatial scale is altered due to ambient factors. The results show for the first time that a parasitoid switches between an interactive combined use of mechanosensory and visual cues to a nearly exclusive use of visual cues at low temperatures when vibrational sounding becomes unreliable. Under optimum environmental conditions, visual and vibrational orientation have the same relative importance, which confirmed previous results in the species (Fischer et al. 2001). At the low and the high end of the temperature scale, however, the relative importance of vibrational cues declines significantly.

Switching between sensory modalities on the same spatial scale depending on environmental conditions in other animals has been hitherto largely focused on ambient lighting conditions. A common example is the combined visual orientation of birds during daylight and predominant magnetic orientation during darkness (Able 1991; Wiltschko and Wiltschko 1995; Walker et al. 2002). In the absence of light, the bumblebee Bombus impatiens switches from vision to a combined magnetic and chemical orientation in order to find the nest (Chittka et al. 1999). Also amphibians, as the alpine newt Triturus alpestris, may switch from vision during daytime to magnetic orientation during nocturnal homing (Diego-Rasilla et al. 2005). In darkness, the electric fish Gnathonemus petersii uses active electrolocation for prey detection whereas vision can become the dominant sense when light is available (Von der Emde and Bleckmann 1998). Changes in the acoustic properties of the environment lead bats, as the Northern bat (Eptesicus nilssonii), to switch from ultrasonic echolocation to visual orientation to avoid clutter, i.e. unwanted echoes from the background (Eklöf et al. 2002). Finally, gravity changes in the human environment can lead to strong shifts of spatial orientation to vision: Whereas vision may compensate the gravity sense and prevent loss of spatial orientation while entering weightlessness, an inversion illusion is almost universal in parabolic flight among blindfolded humans tested for the first time (Lackner 1992). To the authors' knowledge the results of the present study is the first account of a temperature dependent alteration of multisensory orientation.

In nature, mechanosensory host location of parasitic wasps by vibrational sounding is an essential component of short-range detection. This mechanism plays an important role for host searching in an environment of multiple cues (Fischer et al. 2004a). When mechanosensory mechanisms are involved, temperature dependence of host location is especially relevant because they depend on physical properties of the environment 
and on the capability of the insects to either produce or receive signals (e.g. French 1985; Otten et al. 2002; Fischer et al. 2003a). The influence of temperature on vibrational sounding was recently demonstrated in $P$. turionellae as well as in the closely related tropical ichneumonid species Xanthopimpla stemmator (Thunberg) (Kroder et al. 2006; Samietz et al. 2006). In both species the percentage of females responding to the vibrational cue and the quantitative insertion activity decreased down- and upwards of a temperature optimum. Also the precision decreases beyond a certain temperature limit-in P. turionellae at and below $10^{\circ} \mathrm{C}$ and at and above $28^{\circ} \mathrm{C}$ (Samietz et al. 2006). A constantly high precision between these temperature limits could be held by a temperature-coupled production of vibrations. The wasps increase the intensity and carrier frequency with decreasing ambient temperature to compensate a presumably diminishing sensitivity of mechanoreceptors (Kroder et al. 2007). How the parasitoids deal with temperature when confronted with more than mechanosensory cues was however not tested before. The results of the present study accordingly demonstrate the consequences of the temperature effect in the more complex multisensory orientation and how the wasps deal with changes in the reliability of single senses. Beyond the temperature limits, the less reliable vibrational sounding does not reduce the efficiency of host location if multiple cues are available. Therefore, the efficiency does not alter to the reliability of all involved senses but to the most reliable. Although activity of enzymes involved in the visual process may be affected by temperature, for insect vision such negative temperature effects in the studied thermal range are not known (Willmer et al. 2004).

Few studies have so far investigated the interaction of information from different sensory sources during parasitoid host location on the same spatial scale, and the focus in those studies was on visual combined with chemical cues. The braconid wasp Microplitis croceipes shows a stronger preference after conditioning to a combination of visual and chemical cues, than after conditioning to either one alone (Wäckers and Lewis 1994). In individuals conditioned to both cues, the chemical stimulus was dominant. In the aphidiid wasp Aphidius ervi, the importance of visual and chemical perception of the host is displayed in oviposition behaviour at short range (Battaglia et al. 1993, 2000). The use of visual and chemical cues in multisensory orientation is further demonstrated in the parasitoid flies Apocephalus paraponerae (Morehead and Feener 2000) and Exorista mella (Stireman 2002). The influence of environmental factors on the multisensory use of information in parasitoid host location was hitherto only investigated with respect to changes of the parasitoids behaviour across the different spatial scales of the host location process (Wellings 1993; Völkl 2000; Schwörer and Völkl 2001).

In multisensory orientation of parasitoids, the role of chemical, visual and vibrational cues largely varies with the spatial scale (Völkl 2000; Fischer et al. 2001; Schwörer and Völkl 2001). Volatile chemicals as well as vision are important for host microhabitat detection (Michaud and Mackauer 1994; Battaglia et al. 2000; Völkl 2000) whereas contact chemicals as well as vibrational cues can only be detected after landing on the substrate (Meyhöfer et al. 1997; Dutton et al. 2000; Fischer et al. 2001; Otten et al. 2002). The females of $P$. turionellae are known to use lightness contrasts in visual host location (Fischer et al. 2004b), and the detection range of achromatic cues is usually larger than of chromatic cues (Hempel de Ibarra et al. 2001). Consequently, in $P$. turionellae females the orientation towards a potential host habitat-here the plant-stem model-should be primarily visually directed-especially if a visual cue in the habitat is available that may indicate a possible host pupae concealed in the substrate. The wasps then antennate on the plant stem and locate potential hosts by both vibrational sounding and visual orientation. Vision is used both before and after landing on a host patch, whereas mechanosensory information is only accessible after landing. Therefore, the higher visual responsiveness over all temperatures in our present experiments likely results from the lacking role of vibrational sounding before contact is made with the plant-stem model.

The ovipositor insertion activity of $P$. turionellae, i.e. the average number of insertions per responding female, changes with ambient temperature, even though the parasitoids were allowed to use visual and vibrational cues simultaneously. The insertion activity seems to increase continuously from 8 to $28^{\circ} \mathrm{C}$ but the activity at $28^{\circ} \mathrm{C}$ is not much higher than at $18^{\circ} \mathrm{C}$ and a maximum could be assumed between these two temperatures. Such a temperature dependence of insertion activity with a maximum between 20 and $26^{\circ} \mathrm{C}$ was previously revealed in females of this species, which exclusively use vibrational sounding during host location (Samietz et al. 2006; Kroder et al. 2006). This analogy between multisensory orientation in the current work and single use of a searching mechanism in previous studies makes evident that insertion activity does not solely depend on a certain sense of host location but also on the general physical activity of the insects. With a higher physical activity at high temperatures the searching process accelerates and allows the wasps to 
insert the ovipositor more often than at lower temperatures.

In the comparison of the relative importance of cues at medium temperature of $18^{\circ} \mathrm{C}$, the $P$. turionellae females showed no preference for one of the cues; they were equally attracted to both, the vibrational and the visual cue. This finding confirms the previously stated interaction between visual orientation and vibrational sounding after landing (Fischer et al. 2001). Decreasing reliability due to changed environmental conditions leads to a decreasing relative importance of that cue. As the reliability of vibrational sounding decreases, the relative importance of visual cues increases at the temperature extremes and especially at the low temperature limit of host location. Consequently changes in reliability between two cues used (visual and vibrational) that are differently impaired by ambient factors obviously lead the wasps to alter multisensory orientation and switch to the cue, more reliable under given environmental conditions (visual).

Finally, while the precision of vibrational sounding alone is negatively influenced by too low and too high temperatures (Samietz et al. 2006; cf. above), the overall precision of ovipositor insertions in the present study on the basis of visual and vibrational orientation is not affected by temperature-even when the females of $P$. turionellae switch to only one of the available cues for host location. Even with the observed high individual variability of precision, these results show that the parasitoids may fully compensate the loss of one cue if another reliable cue is available on the same spatial scale.

Acknowledgments We are grateful to Kathrin Tschudi-Rein, John Hildebrand, and the anonymous referees for valuable comments on earlier drafts of the paper. The study was supported by a grant of the ETH Department of Agriculture and Food Sciences to Silvia Dorn. This work complies with the current laws of Switzerland where the experiments were carried out.

\section{References}

Able KP (1991) Common themes and variations in animal orientation systems. Amer Zool 31:157-167

Battaglia D, Pennacchio F, Marincola G, Tranfaglia A (1993) Cornicle secretion of Acyrthosiphon pisum (Homoptera, Aphididae) as a contact kairomone for the parasitoid Aphidius ervi (Hymenoptera, Braconidae). Eur $\mathrm{J}$ Entomol 90:423-428

Battaglia D, Poppy G, Powell W, Romano A, Tranfaglia A, Pennacchio F (2000) Physical and chemical cues influencing the oviposition behaviour of Aphidius ervi. Entomol Exp Appl 94:219-227

Broad GR, Quicke DLJ (2000) The adaptive significance of host location by vibrational sounding in parasitoid wasps. Proc $\mathrm{R}$ Soc Lond Ser B 267:2403-2409
Chittka L, Williams NM, Rasmussen H, Thomson JD (1999) Navigation without vision: bumblebee orientation in complete darkness. Proc R Soc Lond Ser B 266:45-50

Diego-Rasilla FJ, Luengo RM, Phillips JB (2005) Magnetic compass mediates nocturnal homing by the alpine newt, Triturus alpestris. Behav Ecol Sociobiol 58:361-365

Dutton A, Mattiacci L, Dorn S (2000) Plant-derived semiochemicals as contact host location stimuli for a parasitoid of leafminers. J Chem Ecol 26:2259-2273

Eklöf J, Svensson AM, Rydell J (2002) Northern bats (Eptesicus nilssonii) use vision but not flutter-detection when searching for prey in clutter. Oikos 99:347-351

Fischer S, Samietz J, Dorn S (2003a) Efficiency of vibrational sounding in parasitoid host location depends on substrate density. J Comp Physiol A 189:723-730

Fischer S, Samietz J, Dorn S (2004a) Host location of a pupal parasitoid in a tritrophic system to a model offering mechanosensory cues only. J Insect Behav 17:191-199

Fischer S, Samietz J, Wäckers FL, Dorn S (2001) Interaction of vibrational and visual cues in parasitoid host location. $\mathrm{J}$ Comp Physiol A 187:785-791

Fischer S, Samietz J, Wäckers FL, Dorn S (2003b) Perception of achromatic cues during host location of a pupal parasitoid. Entomol Exp Appl 106:63-66

Fischer S, Samietz J, Wäckers FL, Dorn S (2004b) Perception of chromatic cues during host location by the pupal parasitoid Pimpla turionellae (L.) (Hymenoptera: Ichneumonidae). Environ Entomol 33:81-87

French AS (1985) The effects of temperature on action-potential encoding in the cockroach tactile spine. J Comp Physiol A 156:817-821

Godfray HCJ (1994) Parasitoids. Princeton University Press, NJ

Hempel de Ibarra N, Giurfa M, Vorobyev M (2001) Detection of coloured patterns by honeybees through chromatic and achromatic cues. J Comp Physiol A 187:215-224

Kroder S, Samietz J, Dorn S (2006) Effect of ambient temperature on mechanosensory host location in two parasitic wasps of different climatic origin. Physiol Entomol 31:299-305

Kroder S, Samietz J, Schneider D, Dorn S (2007) Adjustment of vibratory signals to ambient temperature in a host-searching parasitoid. Physiol Entomol (in press). DOI 10.1111/ j.13653032.2006.00551.x

Lackner J (1992) Spatial orientation in weightless environments. Perception 21:803-812

Meyhöfer R, Casas J, Dorn S (1997) Mechano- and chemoreceptors and their possible role in host location behavior of Sympiesis sericeicornis (Hymenoptera: Eulophidae). Ann Entomol Soc Am 90:208-219

Michaud JP, Mackauer M (1994) The use of visual cues in host evaluation by aphidiid wasps. Entomol Exp Appl 70:273-283

Morehead SA, Feener DH Jr (2000) Visual and chemical cues used in host location and acceptance by a dipteran parasitoid. J Insect Behav 13:613-625

Otten H, Wäckers FL, Isidoro N, Romani R, Dorn S (2002) The subgenual organ in Pimpla turionellae L. (Hymenoptera: Ichneumonidae): Ultrastructure and behavioural evidence for its involvement in vibrational sounding. Redia 85:61-76

Pfannenstiel RS, Browning HW, Smith JW Jr (1992) Searching behavior of Pediobius furvus (Hymenoptera: Eulophidae) for Eoreuma loftini (Lepidoptera: Pyralidae) in sugarcane. J Econ Entomol 85:384-388

Potting RPJ, Overholt WA, Danso FO, Takasu K (1997) Foraging behavior and life history of the stemborer parasitoid Cotesia flavipes (Hymenoptera: Braconidae). J Insect Behav 10:13-29

R Developement Core Team (2005) R: a language and environment for statistical computing. R Foundation for Statistical 
Computing, Vienna. http://www.R-project.org (21 December 2005)

Rott AS, Häckermann J, Brand N, Vallat A, Dorn S (2005) Parasitoid exploitation of the seasonal variation in host plant volatile emission for herbivore location. Entomol Exp Appl 115:199-205

Samietz J, Kroder S, Schneider D, Dorn S (2006) Ambient temperature affects mechanosensory host location in a parasitic wasp. J Comp Physiol A 192:151-157

Schwörer U, Völkl W (2001) Foraging behavior of Aphidius ervi (Haliday) (Hymenoptera: Braconidae: Aphidiinae) at different spatial scales: Resource utilization and suboptimal weather conditions. Biol Control 21:111-119

Smith JW Jr, Wiedenmann RN, Overholt WA (1993) Parasites of lepidopteran stemborers of tropical gramineous plants. ICIPE Science Press, Nairobi

Stireman JO (2002) Host location and selection cues in a generalist tachinid parasitoid. Entomol Exp Appl 103:23-34

Vet LEM, Wäckers FL, Dicke M (1991) How to hunt for hiding hosts: the reliability-detectability problem in foraging parasitoids. Neth J Zool 41:202-213

Vinson SB (1998) The general host selection behavior of parasitoid hymenoptera and a comparison of initial strategies utilized by larvaphagous and oophagous species. Biol Control 11:79-96
Völkl W (2000) Foraging behaviour and sequential multisensory orientation in the aphid parasitoid, Pauesia picta (Hym., Aphidiidae) at different spatial scales. J Appl Entomol 124:307-314

Von der Emde G, Bleckmann H (1998) Finding food: senses involved in foraging for insect larvae in the electric fish Gnathonemus petersii. J Exp Biol 201:969-980

Wäckers FL, Lewis WJ (1994) Olfactory and visual learning and their combined influence on host site location by the parasitoid Microplitis croceipes (Cresson). Biol Control 4:105112

Wäckers FL, Mitter E, Dorn S (1998) Vibrational sounding by the pupal parasitoid Pimpla (Coccygomimus) turionellae: an additional solution to the reliability-detectability problem. Biol Control 11:141-146

Walker MM, Dennis TE, Kirschvink JL (2002) The magnetic sense and its use in long-distance navigation by animals. Curr Opin Neurobiol 12:735-744

Wellings PW (1993) Foraging behavior in aphid parasitoids-spatial scale and resource assessment. Eur J Entomol 90:377382

Willmer PC, Stone G, Johnston I (2004) Environmental physiology of animals. Blackwell Science, London

Wiltschko R, Wiltschko W (1995) Magnetic orientation in animals. Springer, New York 